\title{
Airway responsiveness to histamine and methacholine: relationship to minimum treatment to control symptoms of asthma
}

\author{
EF JUNIPER, PA FRITH, FE HARGREAVE \\ From the Regional Chest and Allergy Unit, Department of Medicine, St Joseph's Hospital and \\ McMaster University, Hamilton, Ontario
}

ABSTRACT We have prospectively examined in 51 patients the relationship between the level of airway responsiveness to histamine and methacholine and the minimum medications required to control asthma. First we determined the least medication that was required to control symptoms so that they did not disturb sleep, were not present on waking, and did not require use of inhaled salbutamol $(200 \mu \mathrm{g})$ more than four times daily. When baseline $\mathrm{FEV}_{1}$ was $>70 \%$ of predicted and when there had been no respiratory infection or allergen exposure for six weeks, histamine and methacholine inhalation tests were carried out on separate days to determine the provocation concentration causing a fall in $\mathrm{FEV}_{1}$ of $20 \%\left(\mathrm{PC}_{20}\right)$. There was a close correlation between the $\mathrm{PC}_{20}$ to the two agents. The patients were grouped into 1 , those who required no medication; 2 , those who required salbutamol $(200 \mu \mathrm{g})$ occasionally but not daily; 3 , those who required daily salbutamol; and 4 , those who required additional beclomethasone dipropionate. The mean $\mathrm{PC}_{20}$ was highest in group 1 and lowest in group 4; there was a significant difference between each group. The results indicate that airway responsiveness to vasoactive amines is either an important determinant of the severity of asthma and the medication requirements or a consequence of the severity of asthma. They raise the possibility that measurement of responsiveness may be useful in some patients with established asthma to substantiate or question medication needs.

Non-allergic (non-specific) airway responsivenss to histamine and methacholine is increased in virtually all, if not all, subjects with current symptoms of asthma. ${ }^{1}$ The degree of increase is related to the severity of symptoms, ${ }^{2}$ the number of previous hospital admissions, ${ }^{3}$ and the ease with which asthma is induced by non-allergic ${ }^{4-6}$ and allergic ${ }^{7}$ stimuli. Possibly also it may be related to treatment requirements. ${ }^{3} 8$ In a previous retrospective study we observed, in a group of asthmatics, a relationship between the level of airway responsiveness to histamine and the amount of treatment required to control symptoms. However there was a variation in responsiveness among patients requiring the same treatment. ${ }^{1}$

The objective of the present study was to treat a group of patients with asthma in a standard way to determine the minimum medication required to control symptoms and then to examine prospectively

Address for reprint requests: Dr FE Hargreave, Regional Chest and Allergy Unit, St Joseph's Hospital, 50 Charlton Avenue East, Hamilton, Ontario L8N 1Y4, Canada. the relationship between the amount of treatment and airway responsiveness to histamine and methacholine. Factors known to influence responsiveness, such as airway calibre, recent respiratory infection, and allergen exposure were carefully controlled.

\section{Methods}

Fifty-one adults who were attending the Chest and Allergy Clinic at St Joseph's Hospital and who were under our care were studied (table). Their ages ranged from 15-70 years; 29 were female. All gave a history of episodic dyspnoea and wheezing consistent with the presence of asthma. All had previously had variability in forced expired volume in one second $\left(\mathrm{FEV}_{1}\right)$ of greater than $20 \%$ either spontaneously or after bronchodilator. All were non-smokers and none had features of other respiratory disease. Twenty-one were atopic as indicated by one or more wheal and flare skin respones to prick tests with $\mathbf{1 6}$ common allergen extracts. The extracts were of Alternaria tenuis, Hormodendrum, dog hair and 


\begin{tabular}{|c|c|c|c|c|}
\hline & \multicolumn{4}{|l|}{ Treatment groups } \\
\hline & No medications & $\begin{array}{l}\text { Bronchodilator prn, } \\
\text { not daily }\end{array}$ & Bronchodilator daily & Inhaled beclomethasone \\
\hline Number of patients & 14 & 10 & 10 & 17 \\
\hline Age (years) mean & $32 \cdot 9$ & $33 \cdot 6$ & $42 \cdot 1$ & $52 \cdot 8$ \\
\hline SD & $8 \cdot 9$ & $14 \cdot 2$ & $13 \cdot 4$ & $9 \cdot 6$ \\
\hline Sex (female) & 10 & 6 & 5 & 8 \\
\hline Atopic* (number) & 12 & 6 & 2 & 1 \\
\hline $\mathrm{FEV}_{1}(\mathrm{l})$ mean & $2 \cdot 85$ & $3 \cdot 18$ & 2.56 & $2 \cdot 1$ \\
\hline SD & 0.66 & 0.93 & 0.80 & 0.74 \\
\hline $\mathrm{FEV}_{1}(\%$ predicted $)$ mean & $95 \cdot 2$ & $98 \cdot 6$ & $87 \cdot 2$ & $82 \cdot 4$ \\
\hline SD & $8 \cdot 1$ & $12 \cdot 2$ & $12 \cdot 7$ & $19 \cdot 9$ \\
\hline $\mathrm{PC}_{20}$ histamine $(\mathrm{mg} / \mathrm{ml})$ mean & $6 \cdot 78$ & 2.93 & 0.86 & 0.42 \\
\hline SD & $2 \cdot 15$ & 1.90 & $2 \cdot 22$ & $2 \cdot 71$ \\
\hline $\mathrm{PC}_{20}$ methacholine $(\mathrm{mg} / \mathrm{ml})$ mean & $6 \cdot 32$ & $2 \cdot 52$ & 0.85 & 0.41 \\
\hline SD & $2 \cdot 48$ & 1.92 & $2 \cdot 56$ & $2 \cdot 87$ \\
\hline
\end{tabular}

* Patients were regarded as atopic if they had one or more wheal and flare responses to prick tests with 16 common allergen extracts (see text).

dander, cat hair and dander, horse hair and dander, mixed feathers, and house dust mixture w/v 1:10 (Hollister Stier Laboratories), Aspergillus w/v 1:20, Dermatophagoides farinae 1:100, milk, whole egg, shell fish and mixed nuts $1: 10$, trees, grasses and Eastern ragweeds $25000 \mathrm{NU} / \mathrm{cc}$ (Bencard Allergy Service). No subject was sensitised to house dust or $D$ farinae.

In each patient the minimum medication required to control symptoms was established in a standard way. None was given if symptoms were absent or not troublesome. More pronounced symptoms were treated with salbutamol inhaler $200 \mu \mathrm{g}$ when needed up to four times daily. If this was not sufficient and if symptoms were not too severe, beclomethasone dipropionate inhaler was added in a dose of $100 \mu \mathrm{g}$ four times daily. If symptoms were very severe or if salbutamol plus beclomethasone did not control them, a short course of prednisone was added. Once symptoms were controlled the dose of beclomethasone was reduced at weekly intervals to determine the minimum that was needed to maintain control.

Symptoms were considered to be under control when they did not disturb sleep, were not present on waking in the morning, did not limit normal daily activities, and did not require use of salbutamol inhaler in a dose of more than $800 \mu \mathrm{g}$ daily.

When symptoms were controlled on a minimum of medication for at least six weeks, one inhalation test with histamine and one with methacholine were carried out on separate days within one week. Care was taken to control environmental factors and subject characteristics which are known or presumed to influence responses to inhalation tests. Thus for six weeks before the study subjects were not exposed to any allergens to which they were sensitive and had no symptoms of respiratory tract infection. Inhaled salbutamol was withheld for six hours before each test but beclomethasone was continued in the same dose Tests were carried out at the same time of day and $\frac{\tilde{\omega}}{\omega}$ before each test subjects avoided vigorous exerciseand cold air. Tests were not carried out on days of heavy air pollution. The initial $\mathrm{FEV}_{1}$ was greaterthan $70 \%$ predicted in all but five subjects who had aO severe increase in responsiveness to histamine and methacholine; in these it was initially above $60 \%$ and

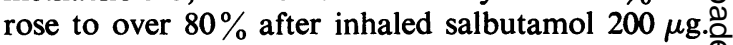
Variation of initial FEV ${ }_{1}$ on the two study days was@ less than $10 \%$.

Histamine and methacholine inhalation tests were 3 carried out by the method described by Cockcroft et $a l^{1}$ and Juniper et al. ${ }^{9}$ Aerosols of the test solu: tions were produced by the same Wright nebuliser which gave an output of $0.13 \mathrm{ml} / \mathrm{min}$ and a particleo size of $1.5 \mu \mathrm{m}$ aerodynamic mass median diameter. $\mathrm{A}_{x}^{0}$ nose clip was worn and the aerosol was inhaled byo tidal breathing for two minutes. An aerosol of normal saline was inhaled first, followed at five-o minute intervals by two-fold increasing concentrations of either histamine acid phosphate or metha-윽 choline (from 0.03 to $16 \mathrm{mg} / \mathrm{ml}$ ). The $\mathrm{FEV}_{1}$ was measured before and at 0.5 and $1.5 \mathrm{~min}$ after each inhalation. Inhalations were discontinued when then FEV $_{1}$ had fallen $20 \%$ or more below the lowese post-saline value. The provocation concentration 5 producing a fall in FEV 1 of $20 \%\left(\mathrm{PC}_{20}\right)$ was react off the log-dose response curve by linear interp? olation of the last two points. The relationship beo tween the response to histamine and response to methacholine was determined using least squares? regression analysis. Patients were grouped accord $=0$ ing to their minimum medication requirement into four groups: 1 , those requiring no medi $\stackrel{\mathbb{Q}}{\circ}$ cation; 2, bronchodilator more than once pe $\mathbb{Q}$ week but less than once per day; 3 , bronchodilatoge daily; and 4 , bronchodilator plus beclomethasone Difference in mean $\mathrm{PC}_{20}$ and $\mathrm{FEV}_{1}$, as a percent of 
predicted normal, between treatment groups was examined by one-way analysis of variance and Student's $t$ test.

\section{Results}

The mean provocation concentration of histamine and methacholine causing a $20 \%$ fall in FEV 1 $\left(\mathrm{PC}_{20}\right)$ in each treatment group was significantly different between each group, being highest in the group on no medication (group 1) and lowest in the group on bronchodilator plus beclomethasone (group 4) (table, fig 1).

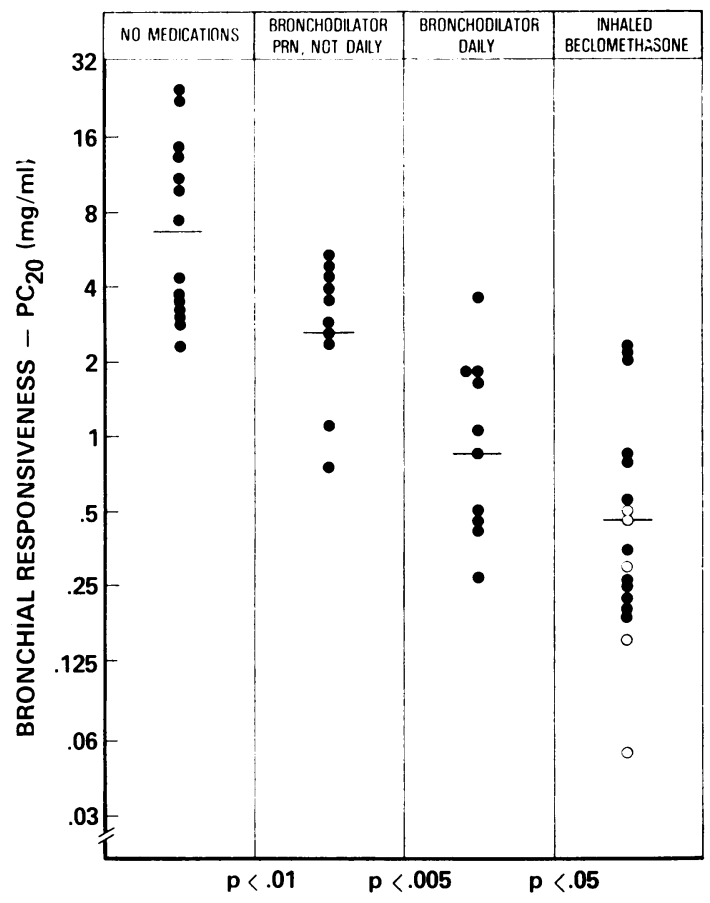

Fig 1 Relationship of $P C_{20}$ (expressed as a mean of the results obtained with histamine and methacholine) to minimum medications required to control symptoms of asthma. Bars represent the mean $P C_{20}$ in each treatment group. Open circles are those patients whose baseline FEV $V_{1}$ was reduced to between 60 and $70 \%$ (and which rose to above $80 \%$ after salbutamol $200 \mu \mathrm{g}$ given after the test).

There was a range in the $\mathrm{PC}_{20}$ of histamine and methacholine in individual patients in each treatment group (fig 1). In patients with a $\mathbf{P C}_{20}>2$ $\mathrm{mg} / \mathrm{ml}$ symptoms of asthma were usually controlled on no medication or bronchodilator occasionally but not daily. Patients with a $\mathrm{PC}_{20}<2 \mathrm{mg} / \mathrm{ml}$ generally required a daily bronchodilator \pm beclomethasone.
The mean $\mathrm{FEV}_{1}$ was highest in group 2 and lowest in group 4 (table); however there were no significant differences in $F E V_{1}$, as a percent of predicted normal, begween the groups $(p>0.05)$.

Bronchial responsiveness to histamine correlated with responsiveness to methacholine $(r=0.96)$ (fig 2). All responses were within one two-fold concentration of the line of identity.

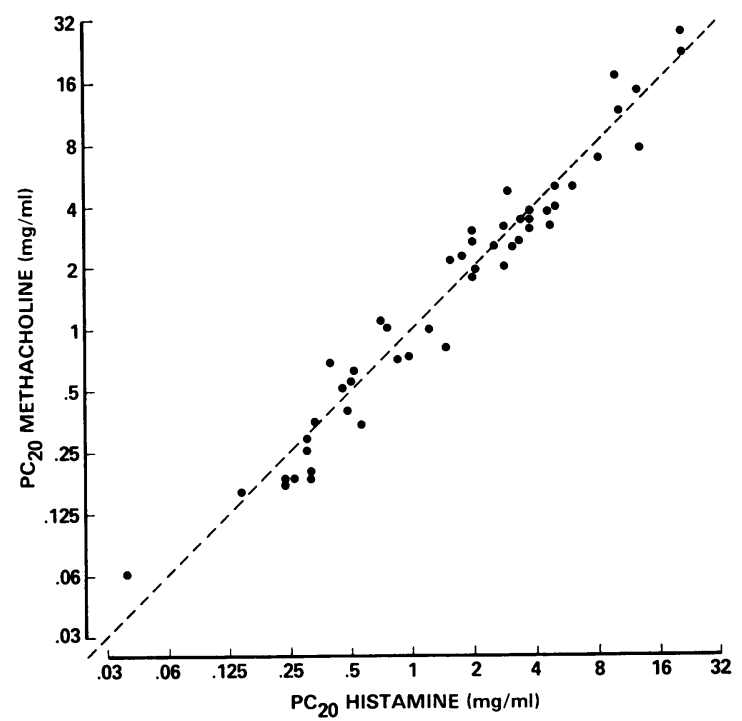

Fig 2 Comparison of airway responsiveness to histamine and methacholine in each patient. Dashed line is the line of identity.

\section{Discussion}

In this study of 51 asthmatics, with well-controlled symptoms and an $\mathrm{FEV}_{1}>70 \%$ predicted, there was a relationship between the level of non-allergic airway responsiveness to histamine or methacholine and the minimum treatment required to control symptoms.

The study has examined prospectively for the first time the relationship between non-allergic airway responsiveness and treatment requirements in asthma. There is evidence that in established asthma the level of hyperresponsiveness remains stable over long periods of time ${ }^{10}$ unless heightened by exposure to respiratory infection, ${ }^{11}$ exposure to allergens ${ }^{12} 13$ or to volatile chemicals $\mathbf{1 4}^{15}$ to which the person is sensitised or, possibly, by exposure to atmospheric pollutants such as oxides of nitrogen ${ }^{16}$ and ozone. ${ }^{17}$ In this study these exacerbating factors were excluded.

Previous retrospective surveys support the results 
of the present study. Thus Townley and coworkers ${ }^{3}$ observed a greater responsiveness in asthmatics who had previously required more medication and Spector and Farr ${ }^{8}$ noticed that more severely hyperresponsive patients required a higher discharge dose of corticosteroids. Cockcroft and coworkers ${ }^{1}$ observed a similar relationship to the one reported in the present study, even though they did not control factors which might influence results as carefully as we did.

The relationship observed indicates that nonallergic airway responsiveness is either an important determinant of the severity of asthma and the medication requirements or a consequence of the severity of asthma. The range in responsiveness between patients in each treatment group suggests that other factors contribute to the severity of asthma. These might include other structural changes such as mucosal oedema and increased secretions; these might have been more important in group 4 who required additional beclomethasone and less important in groups 1-3 because symptoms were controlled by salbutamol alone and $\mathrm{FEV}_{1}$ was more than $70 \%$ predicted. There are also non-pathological differences between patients such as the ability to detect airflow obstruction ${ }^{18}$ or to tolerate symptoms, and differences in lifestyle. A physically active asthmatic will require more medication than a sedentary asthmatic with a similar level of airway responsiveness. In corticosteroid-dependent patients the range of responsiveness may also be increased because corticosteroids may reduce hyperresponsiveness to a greater extent in some patients. ${ }^{10}$

The severity of asthma is usually assessed by history, examination, and measurement of spirometry or peak flow rates. Medication requirements are established by trial. All of the methods of assessment can be misleading. Some patients perceive airflow obstruction poorly, 18 others have lived with a variable airflow obstruction for so long that they do not appreciate disability, while others interpret breathlessness as abnormal when it is not. The physician may misinterpret the severity of symptoms. Physical examination is an insensitive method of assessing severity. ${ }^{19}$ Spirometry may be normal when the person is seen in clinic but low at other times of the day; in the present study $\mathrm{FEV}_{1}$ was greater than $70 \%$ predicted at the time of the inhalation tests in all except five subjects. As a result patients may inadvertently be undertreated or overtreated on the basis of clinical and spirometric information alone.

The results of the present study raise the possibility that measurement of airway responsiveness may be useful as an adjunct to usual clinical assessment of established asthma. The overlap of responsiveness in each treatment group indicates that measurement $\stackrel{9}{\frac{9}{0}}$ cannot be used on its own to determine actual 당 treatment requirements in individual patients. How- $\overline{\frac{\sigma}{\omega}}$ ever, the observation that a $\mathbf{P C}_{20}$ of greater than $\widetilde{\Phi}$ $2 \mathrm{mg} / \mathrm{ml}$ was generally associated with absent or trivial dyspnoea (needing no medication or only $\infty$ salbutamol occasionally but not daily to control $\vec{\circ}$ symptoms) suggests that if such a result were $\overrightarrow{\vec{H}}$ obtained in a patient taking regular salbutamol or $\stackrel{\omega}{\sigma}$ beclomethasone that a further trial of reduction of $\underset{\overrightarrow{2}}{\overrightarrow{2}}$ medication should be tried. Alternatively, if the $\mathrm{PC}_{20} \stackrel{\times}{\mathrm{\omega}}$ was below $2 \mathrm{mg} / \mathrm{ml}$ and the patient was receiving no medication or only a bronchodilator occasionally the $\infty$ clinical features should be reviewed to determine ov whether the severity of asthma had been under- $O$ estimated and whether a trial of more regular medication should be considered. We have begun to $\supset$ use histamine and methacholine tests in this way inc our clinical practice and have found them useful $\stackrel{\leftarrow}{\infty}$ especially where there is doubt about the severity $\vec{\longrightarrow}$ of asthma from the history and the spirometry $\stackrel{\infty}{\infty}$ measured in clinic is normal.

We are grateful to our patients for participating in the study, and to Dr NL Jones and Dr J Dolovich for $\overline{0}$ help with preparing the manuscript. This work was supported by grant no MA5888 from the Medical $\stackrel{\mathbb{Q}}{\unrhd}$ Research Council of Canada.

\section{References}

${ }^{1}$ Cockcroft DW, Killian DN, Mellon JJA, Hargreave FE. Bronchial reactivity to inhaled histamine: a method and clinical survey. Clin Allergy 1977;7:235-43.

${ }_{2}$ Makino S. Clinical significance of bronchial sensitivity to $\times$ acetylcholine and histamine in bronchial asthma. $J$ 윽 Allergy 1966;38:127-42.

${ }^{3}$ Townley RG, Ryo UY, Kolotkin BM, Kang B. Bronchial sensitivity to methacholine in current and former asthmatic and allergic rhinitis patients and control subjects. J Allergy Clin Immunol 1975;56:429-42.

${ }^{4}$ Eggleston PA. A comparison of the asthmatic response to $D$ methacholine and exercise. J Allergy Clin Immunol 1979;음 63:104-10.

${ }^{5}$ Anderton RC, Cuff MT, Frith PA et al. Bronchial respon- N siveness to inhaled histamine and exercise. J Allergy Clin Immunol 1979;63:325, 315-20.

${ }^{6}$ Horton DJ, Suda WL, Kinsman RA, Souhrada J, Spector N SL. Bronchoconstrictive suggestion in asthma: a role for $\omega$ airways hyperactivity and emotions. Am Rev Respir Dis 1978;117:1029-38.

7 Cockcroft DW, Ruffin RE, Frith PA et al. Determinants of allergen-induced asthma: dose of allergen, circulating IgE antibody, and bronchial responsiveness to inhaled? histamine. Am Rev Respir Dis 1979;120:1053-8.

${ }^{8}$ Spector SL, Farr RS. A comparison of methacholine and histamine inhalations in asthmatics. $J$ Allergy Clin Immunol 1975;56:308-16.

9 Juniper EF, Frith PA, Dunnett C, Cockcroft DW, @ Hargreave FE. Reproducibility and comparison of responses to inhaled histamine and methacholine. Thorax 1978;33:705-10. 
10 Juniper EF, Frith PA, Hargreave FE. Long-term stability of nonspecific airway responsiveness to histamine and effect of beclomethasone. Am Rev Respir Dis 1980;121S: 76A.

${ }^{11}$ Little JW, Hall WJ, Douglas RG Jr, Mudholkar GS, Speers DM, Patel K. Airway hyperreactivity and peripheral airway dysfunction in influenza A infection. $A m$ Rev Respir Dis 1978;118:295-303.

${ }^{12}$ Cockcroft DW, Ruffin RE, Dolovich J, Hargreave FE. Allergen-induced increase in non-allergic bronchial reactivity. Clin Allergy 1977;7:503-13.

${ }^{13}$ Cartier A, Bandouvakis J, Ryan G, Dolovich J, Hargreave FE. Asthma and increased nonallergic bronchial responsiveness to methacholine during natural exposure to ragweed pollen. Am Rev Respir Dis 1980;121S:61A.

14 Cockcroft DW, Cotton DJ, Mink JT. Nonspecific bronchial hyperreactivity after exposure to western red cedar.
Am Rev Respir Dis 1979;119:505-10.

${ }^{15}$ Lam S, Wong R, Yeung M. Nonspecific bronchial reactivity in occupational asthma. J Allergy Clin Immunol 1979;63:28-32.

${ }^{16}$ Orehek J, Massari JP, Gayrard P, Grimaud C, Charpin J. Effect of short-term, low level nitrogen dioxide exposure on bronchial sensitivity of asthmatic patients. $J$ Clin Invest 1976;57:301-7.

17 Golden JA, Nadel JA, Boushey HA. Bronchial hyperirritability in healthy subjects after exposure to ozone. Am Rev Respir Dis 1978;118:287-94.

${ }^{18}$ Rubinfeld AR, Pain MCF. Perception of asthma. Lancet $1976 ; 1: 882-4$.

19 Shim CS, Williams MH Jr. Evaluation of the severity of asthma: patients versus physicians. Am J Med 1980; 68:11-3. 